\title{
Simvastatin ve mevastatin'in anjiogenez inhibisyonu üzerine etkilerinin koryoallantoik membran modelinde araştırılması
}

\author{
Investigating the effects of simvastatin and mevastatin on angiogenesis in \\ chorioallantoic membrane model
}

\author{
Zeliha Beşikçi Ödemiş, Tijen Kaya Temiz, Ezgi Balcı, Mesut Parlak, Ahmet Altun* \\ Tıbbi Farmakoloji Anabilim Dalı (Uzm. Ecz. Z. B. Ödemiş, Prof. Dr. T. K. Temiz, Dr. E. Balcı, \\ Dr. M. Parlak, Yrd. Doç. Dr. A. Altun), Cumhuriyet Üniversitesi Tıp Fakültesi, TR-58140 Sivas
}

\begin{abstract}
Özet
Amaç. Bu çalışmanın amacı klinik tedavide sık olarak kullanılan statinlerden olan simvastatin ve mevastatinin anjiogenez inhibisyonu üzerine etkilerini döllenmiş tavuk yumurtaları üzerinde, koryoallantoik membran modelini (CAM modeli) kullanarak kıyaslamaktır. Yöntem. Çalışmada Ross 308 cinsi döllenmiş tavuk yumurtaları kullanıldı. Döllenmiş tavuk yumurtaları $37,5^{\circ} \mathrm{C}^{\prime} \mathrm{de}$ $\% 80$ rölatif nemli ortamda horizontal pozisyonda inkübe edildi. Kuluçkanın beşinci gününde yumurtanın künt tarafından enjektör yardımıyla $5 \mathrm{~mL}$ albumin alındı ve yumurtanın diğer ucundan 2-3 cm çapında kabuk kesilerek çıkarıldı. Kabuktaki bu açıklık laboratuvar filmi ile kapatıldı ve koryoallantoik membran modeli yaklaşık $2 \mathrm{~cm}$ çapa ulaşana kadar 72 saat daha inkübe edildi. Her bir yumurtaya koryoallantoik membran üzerine etken madde içeren bir pellet yerleştirildi. İlaç uygulamasindan (bevacizumab, simvastatin ve mevastatin; $10^{-4} \mathrm{M}, 10^{-5} \mathrm{M}$ ve $10^{-6} \mathrm{M}$ konsantrasyon) sonra yumurtalar 24 saat daha inkübe edildi. Stereoskopik mikroskop altında Bürgermeister ve arkadaşlarının skorlama sistemi kullanılarak pellet uygulama bölgesindeki damar yapısı değerlendirildi. Bulgular. Çalışmamızda negatif kontrol olarak ilaç içermeyen agar diskler kullanıldı. Negatif kontrol yumurtalarının hiç birinde anjiogenez engellenmedi ve anti-anjiogenik etki puanı " 0 " olarak bulundu. Pozitif kontrol olarak antianjiogenik etkinliği kanıtlanmış bevacizumab kullanıldı. Bevacizumab'in $10^{-4} \mathrm{M}, 10^{-5} \mathrm{M}$ ve $10^{-6} \mathrm{M}$ konsantrasyonlarında antianjiogenetik skor değerleri sırasıyla 1,58 , 1,55 ve 1,00 olarak bulundu. Simvastatinin ve mevastatinin $10^{-4} \mathrm{M}, 10^{-5} \mathrm{M}$ ve $10^{-6} \mathrm{M}$ konsantrasyonları için ortalama antianjiyogenik skor değerleri sırası ile $0,93,0,66,0,53$ ve $1,0,0,80$ ve 0,66 olarak bulundu. Hem simvastatinin hem de mevastatinin her üç konsantrasyonunun da anti anjiogenik etkiye sahip olduğu saptandı. Bu iki ilacın $10^{-4} \mathrm{M}$ konsantrasyonlarının meydana getirmiş olduğu anti anjiogenik etki gücü arasında anlamlı bir fark bulunamadı. Ancak azalan konsantrasyonlar birbirleri ile karşılaştırıldığında mevastatinin $10^{-5} \mathrm{M}$ ve $10^{-6} \mathrm{M}$ konsantrasyonlarda simvastatine göre daha anlamlı bir anti anjiogenik etki meydana getirdiği saptandi. Sonuç. Sonuç olarak simvastatin ve mevastatin CAM modelinde antiantiogenik etkinlik gösteren statinlerdir. Bu iki statin lipid düşürücü etkileri yanında, anjiogenez inhibisyonu yaparak; plak içi antianjiogenik etkiyle, plak rüptürü ve buna bağlı ciddi komplikasyonlardan da korunma sağlayabilir.
\end{abstract}

Anahtar sözcükler: Simvastatin, mevastatin, koryoallantoik membran modeli, anjiogenez

\begin{abstract}
Aim. The purpose of this study is to compare the effects of Simvastatin and Mevastatin, commonly used statins in clinic practice, on angiogenesis in chorioallontioc membrane models by using fertilized chicken eggs. Methods. In this study, Ross 308, fertilized chicken eggs were used. The fertilized chicken eggs were incubated in horizontal position with environmental conditions of $37.5{ }^{\circ} \mathrm{C}$ temperature and $80 \%$ relative humidity. On the fifth day of the incubation period, $5 \mathrm{ml}$ of albumen was taken through the eggshell with a syringe and a shell piece of $2-3 \mathrm{~cm}$ in diameter was removed from the contrary side of the eggs. The windows on the egg shells were sealed with gelatin and thereafter, the eggs were incubated for 72 more hours to have chorioallontioc membrane models reaching $2 \mathrm{~cm}$ in diameter. The pellets containing active substrate were placed on the chorioallantoic membrane of each egg. After drug administration (bevacizumab, Simvastatin and Mevastatin; $10^{-4} \mathrm{M}, 10^{-5} \mathrm{M}$ ve $10^{-6} \mathrm{M}$ concentration), the eggs were incubated for 24 hours again. Under a stereoscopic microscope, vascular structure around the pellets was
\end{abstract}


evaluated using a scoring system of Bürgermeister et al. Results. Drug-free agar discs were used as negative control in our study. Angiogenesis was not inhibited in any negative control eggs and anti-angiogenic effect score was found as " 0 ". Bevacizumab was used as positive control. In $10^{-4}$ $\mathrm{M}, 10^{-5} \mathrm{M}$ and $10^{-6} \mathrm{M}$ concentrations, antiangiogenic score of Bevacizumab were found 1,58, 1,55 and 1,00 , respectively. For $10^{-4} \mathrm{M}, 10^{-5} \mathrm{M}$ and $10^{-6} \mathrm{M}$ concentrations of Simvastatin and Mevastatin, antiangiogenic scores were found as $0.93,0.66,0.53$ and 1.0, 0.80, 0.66, respectively. Both Mevastatin and Simvastatin were found to have antiangiogenic effects in each three concentrations. There wasn't a significant difference between antiangiogenic effects of these two drugs in $10^{-4} \mathrm{M}$. But when lower concentrations were compared it is found that Mevastatin had significantly higher antiangiogenic effect than Simvastatin at $10^{-5} \mathrm{M}$ and $10^{-6} \mathrm{M}$ concentrations. Conclusion. In conclusion, Simvastatin and Mevastatin are statins which shows antiangiogenic effect in chorioallontioc membrane models. Besides they can the lipid-lowing effects of statins they can also provide. Protection against plaque rupture related serious complication by the intraplaque antiangiogenesis effect

Keywords: Simvastatin, mevastatin, chorioallontioc membrane models, angiogenesis

Geliş tarihi/Received: September 09, 2011; Kabul tarihi/Accepted: April 04, 2012

\section{*İletişim adresi:}

Dr. Ahmet Altun, Tıbbi Farmakoloji Anabilim Dalı, Cumhuriyet Üniversitesi Tıp Fakültesi, TR58140 Sivas. E-posta: aaltun@cumhuriyet.edu.tr

\section{Giriş}

Anjiyogenez daha önceden var olan vasküler sistemden yeni kan damarı oluşum sürecidir. [1] Erişkinlerde, anjiyogenez normalde yara iyileşmesi, doku tamiri ve menstrual siklus gibi birçok fizyolojik süreçte aktif hale geçer. Patolojik anjiogenez ise başta tümörler olmak üzere kollajen doku hastalıkları, retinopatiler ve psöriasis gibi hastalıklarda meydana gelir [2]. Anjiyogenez bir dizi olayı içeren çok basamaklı bir süreçtir. Anjiyogenez, temel fibroblast büyüme faktörü (bFGF), tümör nekroz faktör alfa $(\mathrm{TNF} \alpha)$ ve VEGF gibi anjiyogenik faktörlerin endotel aktivasyonu yapmak üzere çevre dokudan salınımı ile başlar [3]. Proteolitik yıkılma ve endotel hücresi göçünden sonra yeni oluşan kapillerler bazal membranı oluştururlar [4]. Yeni damar yapımı tamamlandıktan sonra anjiyogenik faktörlerde azalma görülürken, anjiyogenez inhibitörlerinde artış gözlenir. Endotel hücreleri tekrar stabil haldedirler ve damarlar kan akımını başlatmaya hazır hale gelmiş olurlar [5]. Simvastatin ve mevastatin insanda, hepatik ve ekstrahepatik kolesterol biyosentezinde hız-kısıtlayıcı basamağı oluşturan HMG-KoA'nın, mevalonata dönüşmesini katalize eden (3S)-hydroxy-3-methylglurarylcoenzyme A (HMG-KoA) redüktaz enzimini kompetitif olarak inhibe ederek koroner arter hastalığı riski olan hastalarda hiperkolesterolemi tedavisinde sıkça reçete edilen ilaçlardır [6-8]. Klinik çalışmalara ve yapılan diğer temel çalışmalara göre bu enzimin inhibisyonu nedeniyle statinlerin kolesterol düşürücü etkilerinden bağımsız olarak çeşitli yararlı etkileri bulunmaktadır. Antitrombotik, antiinflamatuar, antioksidan etki [9] gibi bu

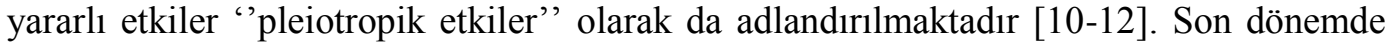
yapılan çalışmalar statinlerin koroner arter hastalığının hem primer hem de sekonder olarak önlenmesinde faydalı olduğunu göstermektedir [13]. Ayrıca statin uygulamasının kısa sürede vazomotor yanıtları güçlendirdiği gösterilmiştir [14, 15]. Hayvan çalışmaları da statinlerin vasküler endotelyal hücreler üzerinde olumlu etkilerinin bulunduğunu göstermektedir $[16,17]$. Son dönemde yapılan çalışmalar diğer statinler gibi mevastatinin de belirli kanser türlerinde kemopreventif ve kemoterapötik olarak kullanılabileceğini ifade etmektedir [18]. Bevacizumab rekombinant humanize edilmiş monoklonal bir IgG1 antikorudur ve VEGF'nin nonspesifik bir inhibitörüdür [19]. Kanser tedavisinde kullanılmak üzere onay almış ilk anti anjiyogenik ajan olan bevacizumabın, faz I çalışmalarında kemoterapi ile birlikte kullanıldığında serum VEGF seviyelerini ölçülemeyecek düzeylere kadar düşürdügü ve farklı tümörlerde büyümeyi inhibe ettiği 
saptanmıştır [20]. Bu bilgiler ışığında biz de çalışmamızda, klinik tedavide sık olarak kullanılan statinlerden simvastatin ve mevastatinin anjiogenez inhibisyonu üzerindeki etkilerini döllenmiş tavuk yumurtaları üzerinde, koryoallontoik membran modelini (CAM modeli) kullanarak kıyaslamayı amaçladık.

\section{Gereç ve yöntem}

\section{Pelletlerin hazırlanması}

Anjiyogenez üzerindeki etkilerini değerlendirmek üzere çalışmamızda birer statin olan, simvastatin ve mevastatin (Sigma St. Louis, MO, USA) ve bir VEGF monoklonal antikoru olan bevacizumab (Altuzan ${ }^{\circledR} 400 \mathrm{mg} / 16 \mathrm{~mL}$ flakon, Roche Müstahzarları Sanayi Anonim Şirketi, İstanbul) kullanılmıştır. İlaçlardan simvastatin ve mevastatin steril distile suda çözülerek hazırlanırken, bevacizumabın kendi sunum formu çözünmüş infüzyon solüsyonu şeklinde kullanıldı. İlaçların uygulamasında üç değişik konsantrasyon $\left(10^{-4} \mathrm{M}, 10^{-5} \mathrm{M}\right.$ ve $\left.10^{-6} \mathrm{M}\right)$ kullanılmıştır. İlaçların önce $10^{-4} \mathrm{M}$ konsantrasyonlarında stok solüsyonları hazırland1. Diğer konsantrasyonlar stok solüsyonun seyreltilmesi ile elde edildi. Simvastatin ve mevastatinin 1:1 kombinasyonlar1, simvastatin ve mevastatinin tek başlarına $10^{-4} \mathrm{M}$ konsantrasyon oluşturan miktarlarının yarısının birlikte uygulanmasıyla oluşturuldu. Diskin $10 \mu \mathrm{L}$ 'lik final hacminde $10^{-4} \mathrm{M}^{\prime} \mathrm{l}$ lk ilaç konsantrasyonunu sağlayacak ilaç miktarını bulabilmek için klasik molarite formülü kullanılmıştır $(\mathrm{M}=\mathrm{m} / \mathrm{V})$. Kolay uygulama için, ilaçlar çözücülerinin içinde tam olarak çözündükten sonra agar ile karıştırılmışlar ve elde edilen bu karışım uygun boyut ve yapıda pelletler elde etmek amacıyla $5 \mathrm{~mm}$ çaplı sirküler paslanmaz çelik yüzeyde $10 \mu \mathrm{L}$ 'lik damlalar şeklinde hazırlanmış ve hızla oda isısına bırakılarak katılaştırılmıştır.

\section{CAM deneyi}

Ross 308 cinsi döllenmiş tavuk yumurtalan Yemsel Tavukçuluk Hayvancıllk Yem Hammaddeleri Sanayi ve Ticaret Anonim Şirketi'nden (Kayseri) temin edilmiştir. Çalışmamız için Cumhuriyet Üniversitesi Tıp Fakültesi Hayvan Etik Kurul'undan onay alınmıştır. Döllenmiş tavuk yumurtaları $37,5^{\circ} \mathrm{C}$ 'de $\% 80$ rölatif nemli ortamda horizontal pozisyonda inkübe edilmiştir. Kuluçkanın beşinci gününde yumurtanın künt tarafından enjektör yardımıyla $5 \mathrm{ml}$ albumin alınmış ve yumurtanın diğer ucundan 2-3 cm çapında kabuk kesilerek çıkarılmıştır. Kabuktaki bu açıklık laboratuvar filmi ile kapatılarak 72 saat daha aynı ortamda inkübe edilmiştir. CAM yaklaşık $2 \mathrm{~cm}$ çapa ulaştığında her bir yumurtaya bir pellet olacak şekilde koryoallantoik membran üzerine etken madde içeren pelletler yerleştirilmiştir. İlaç uygulamasından sonra 24 saatlik ek inkübasyon süresi tanınmıştır. Stereoskopik mikroskop altında Bürgermeister ve ark. [21]'nın skorlama sistemi (Tablo 1) kullanılarak pellet uygulama bölgesindeki damar yapıs1 değerlendirilmiştir.

Tablo 1. Koryoallantoik membran üzerinde anti anjiyogenik etkinin değerlendirilmesi için kullanılan skor değerleri.

\begin{tabular}{|c|c|c|}
\hline Skor & Etki & İzlenim/Açıklama \\
\hline 0 & Yok & Normal embriyo oluşumu, çevre kapillerlere göre değişiklik yok \\
\hline 0,5 & Zayif & $\begin{array}{l}\text { Kapiller damarsız alan yok. Kapillerlerin yoğunluğu azalmış ancak pelletten çok } \\
\text { daha geniş değil. }\end{array}$ \\
\hline 1 & Orta & $\begin{array}{l}\text { Kapillersiz alan az veya kapiller yoğunluk belirli bir alanda azalmış. Etkiler pellet } \\
\text { alanının } 2 \text { katından fazla değil. }\end{array}$ \\
\hline 2 & Kuvvetli & Pelletin etrafinda en az iki kat mesafe olacak şekilde kapillersiz alan mevcut. \\
\hline
\end{tabular}

Her bir test bileşiğinin her bir konsantrasyonu için 15 yumurtaya uygulama yapılmıştır. Her deney grubu için sadece agar içeren pelletlerin uygulandığı negatif kontrol yumurtaları da değerlendirmeye alınmıştır. $\mathrm{Bu}$ anjiogenez modelinde pozitif kontrol, antianjiogenetik özelliği olduğu bilinen bir molekül olan bevacizumab $10^{-6} \mathrm{M}$ konsantrasyonda kullanılmıştır. Tüm testler iki kez tekrarlanmıştır. Sonuç olarak toplam 330 uygulama değerlendirmeye alınmıştır. İlaç gruplarına göre yapılan uygulama sayısı Tablo 2'de gösterilmiştir. 
Tablo 2. Çalışmada kullanılan ilaç gruplarında uygulama sayısı.

\begin{tabular}{llll}
\hline & $10^{-4} \mathrm{M}$ & $10^{-5} \mathrm{M}$ & $10^{-6} \mathrm{M}$ \\
\hline Simvastatin & $15+15$ & $15+15$ & $15+15$ \\
Mevastatin & $15+15$ & $15+15$ & $15+15$ \\
Simvastatin+Mevastatin & $15+15$ & $15+15$ & $15+15$ \\
Pozitif Kontrol (Bevacizumab) & & & $15+15$ \\
\hline Toplam & 330 & & \\
\hline
\end{tabular}

Uygulama sonrası koryoallantoik membran dışına çıkan ve irritasyon gözlenen yumurtalar değerlendirme dışı bırakılmıştır. Koryoallantoik membran üzerinde kullanılan etken maddelerin değerlendirilmesi için Bürgermeister ve ark. [21] tarafından geliştirilen ortalama skorlama sistemi kullanılmıştır. Ortalama skorun belirlenmesi için kullanılan denklem şudur: Ortalama skor $=[$ Yumurta sayısı (Skor 2) X $2+$ Yumurta sayısı (Skor 1) $X$ 1] / [Toplam Yumurta Sayıs1 (Skor 0, 1, 2)]. Bu ortalama skor sistemine göre skor $<0,5$ : antianjiyogenik etki yok, skor 0,5-1: zayıf düzeyde antianjiyogenik etki, skor>1: güçlü antianjiyogenik etki olarak değerlendirilmektedir.

\section{İstatistiksel değerlendirme}

Veriler n (\%) ve ortanca-\%25-75 interkuartil aralık olarak ifade edilmiştir. KolmogorovSmirnov testi ile normal dağılıma uymadıkları tespit edilen verilerin analizi için KruskalWallis ve Mann-Whitney U testleri kullanılmıştır. Yanılma düzeyi 0,05 olarak alınmıştır.

\section{Bulgular}

Çalışmamızda negatif kontrol olarak sadece agar içeren diskler kullanılmıştır. Negatif kontrol yumurtalarının hiç birinde anjiogenez engellenmemiş ve anti-anjiogenetik etki puanı " 0 " olarak bulunmuştur. Bevacizumabın bu deney modelindeki en uygun antianjiogenik konsantrasyonunu bulmak için bevacizumabin $10^{-4} \mathrm{M}, 10^{-5} \mathrm{M}$ ve $10^{-6} \mathrm{M}$ konsantrasyonlarıyla pilot deneyler yapılmış ve antianjiogenetik skor değerleri sırasıyla $1,58,1,55$ ve 1,00 olarak bulunmuştur. Bu veriler 1şı̆̆ında bevacizumabın $10^{-6} \mathrm{M}$ konsantrasyonunun pozitif kontrol olarak kullanılmasına karar verilmiştir.

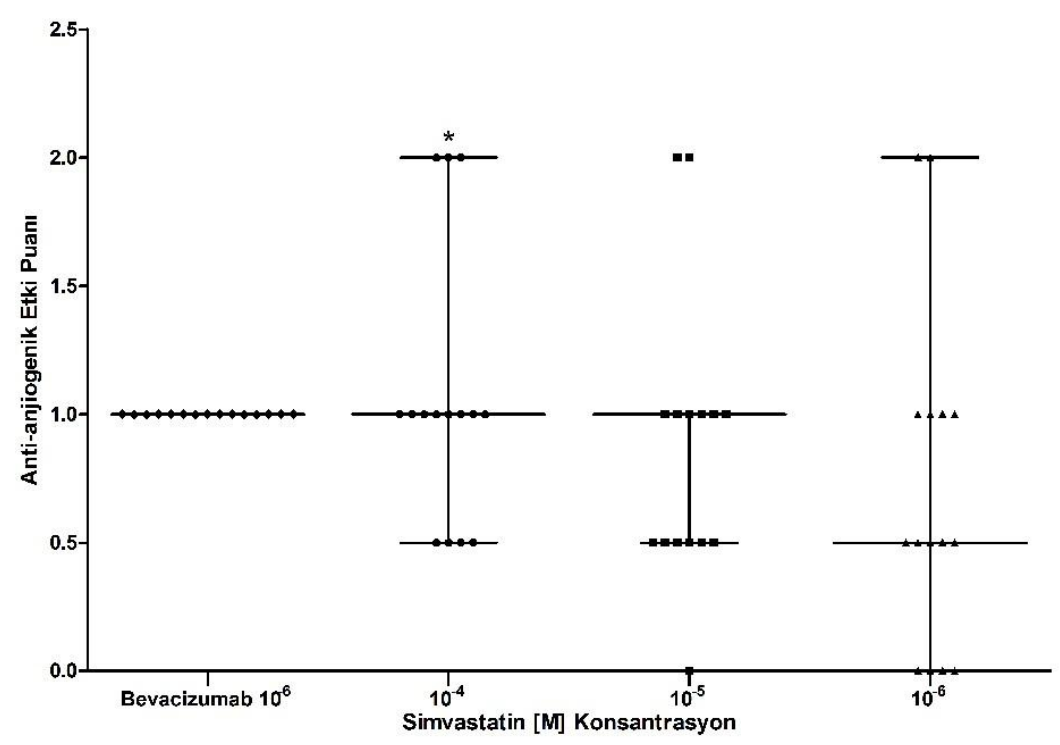

Şekil 1. Simvastatin'in $10^{-4} \mathrm{M}, 10^{-5} \mathrm{M}$ ve $10^{-6} \mathrm{M}$ konsantrasyonlarda antianjiyogenik etki puanları. Veriler skatter grafikte ortanca (interkuartil \%25-75 aralık) olarak sunulmuştur.

Simvastatinin $10^{-4} \mathrm{M}, 10^{-5} \mathrm{M}$ ve $10^{-6} \mathrm{M}$ konsantrasyonları için antianjiyogenik ortalama skor değerleri sırası ile $0,93,0,66$ ve 0,53 olarak bulunmuştur. Simvastatinin $10^{-4} \mathrm{M}$ konsantrasyonda antianjiyogenik etki puanının, $10^{-5} \mathrm{M}$ ve $10^{-6} \mathrm{M}$ konsantrasyonlardan 
istatistiksel olarak anlamlı şekilde daha yüksek $(\mathrm{p}<0,05)$ bulunmuştur. Bulgularımız, kullandığımız araştırma modelinde simvastatinin $10^{-4} \mathrm{M}$ konsantrasyonda belirgin olmak üzere antianjiyogenik etkiye sahip olduğunu göstermiştir.

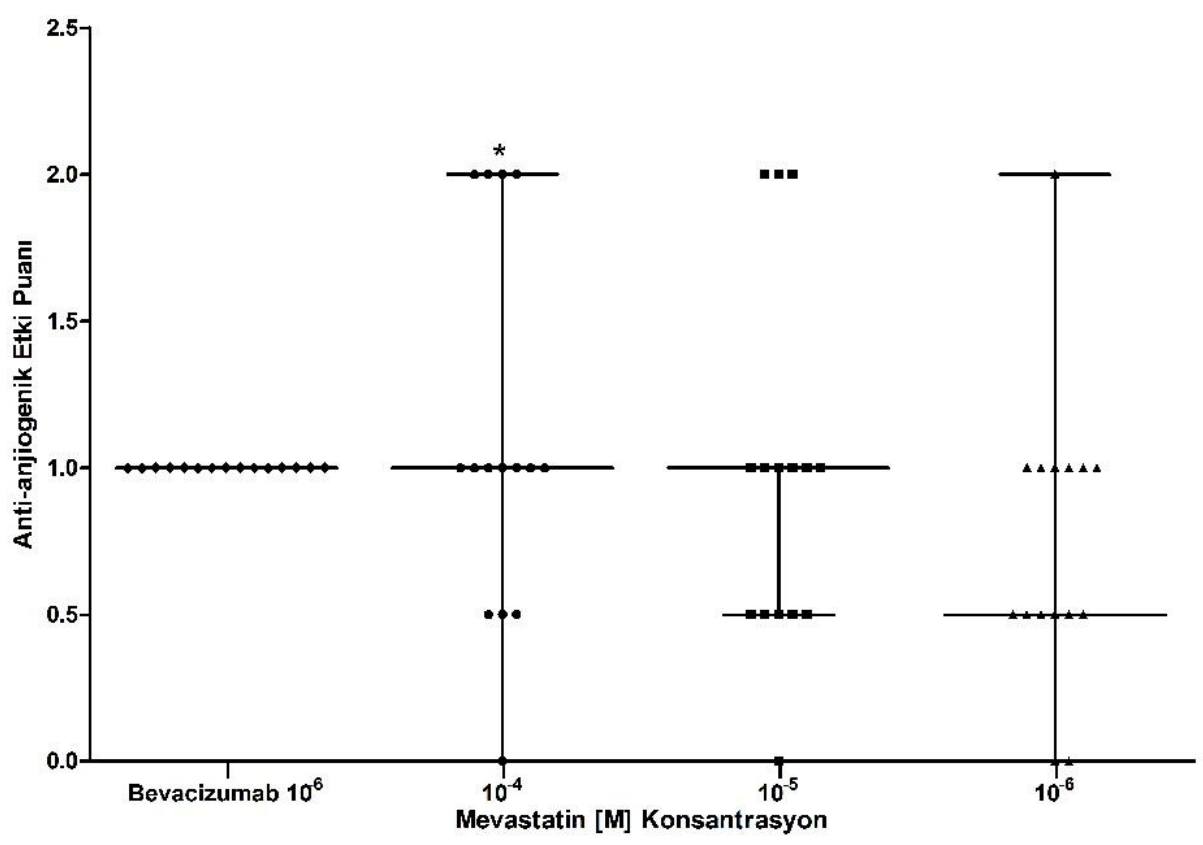

Şekil 2. Mevastatin'in $10^{-4} \mathrm{M}, 10^{-5} \mathrm{M}$ ve $10^{-6} \mathrm{M}$ konsantrasyonlarda antianjiyogenik etki puanları. Veriler skatter grafikte ortanca (interkuartil \%25-75 aralık) olarak sunulmuştur.

Mevastatinin $10^{-4} \mathrm{M}, 10^{-5} \mathrm{M}$ ve $10^{-6} \mathrm{M}$ konsantrasyonları için antianjiyogenik ortalama skor değerleri sırasıyla $1,0,0,80$ ve 0,66 olarak bulunmuştur. Mevastatinin $10^{-4} \mathrm{M}$ konsantrasyonda antianjiyogenik etki puanının $10^{-5} \mathrm{M}$ ve $10^{-6} \mathrm{M}$ konsantrasyonlardan istatistiksel olarak anlamlı şekilde daha yüksek $(\mathrm{p}<0,05)$ bulunmuştur. Bulgularımız, kullandığımız araştırma modelinde mevastatinin $10^{-4} \mathrm{M}$ konsantrasyonda belirgin olmak üzere antianjiyogenik etkiye sahip olduğunu göstermiş̧tir.

Kombinasyonun $10^{-4} \mathrm{M}, 10^{-5} \mathrm{M}$ ve $10^{-6} \mathrm{M}$ konsantrasyonları için antianjiyogenik ortalama skor değerleri sırasıyla $0,96,0,77$ ve 0,59 bulunmuştur. Simvastatin + mevastatin kombinasyonunun $10^{-4} \mathrm{M}$ konsantrasyonda antianjiyogenik etki puanının $10^{-5} \mathrm{M}$ ve $10^{-6} \mathrm{M}$ konsantrasyonlardan istatistiksel olarak anlaml şsekilde daha yüksek $(\mathrm{p}<0,05)$ bulunmuştur. Bulgularımız, kullandığımız araştırma modelinde simvastatin+mevastatin kombinasyonun $10^{-4} \mathrm{M}$ konsantrasyonda belirgin olmak üzere antianjiyogenik etkiye sahip olduğunu göstermiştir.

Hem simvastatinin hem de mevastatinin her üç dozunun da anti anjiojenik etkiye sahip olduğu saptanmıştır. Her iki ilaçta da bu etki $10^{-4} \mathrm{M}$ konsantrasyonda belirgindir ve bu iki ilacın $10^{-4} \mathrm{M}$ konsantrasyonlarının meydana getirmiş olduğu anti anjiojenik etki gücü arasında istatistiksel olarak anlamlı bir fark bulunamamıştır. Ancak azalan konsantrasyonlar birbirleri ile karşılaştırıldı ğında mevastatinin $10^{-5} \mathrm{M}$ ve $10^{-6} \mathrm{M}$ konsantrasyonlarda simvastatine göre istatistiksel olarak daha anlamlı bir anti anjiojenik etki meydana getirdiği saptanmıştır $(\mathrm{p}<0,05)$ (Tablo 3$)$. Simvastatin ve mevastatinin 1:1 kombinasyon uygulamasının ise tek başına uygulanmalarından farklı bir etki meydana getirmediği saptanmıştır $(\mathrm{p}>0,05)$. 


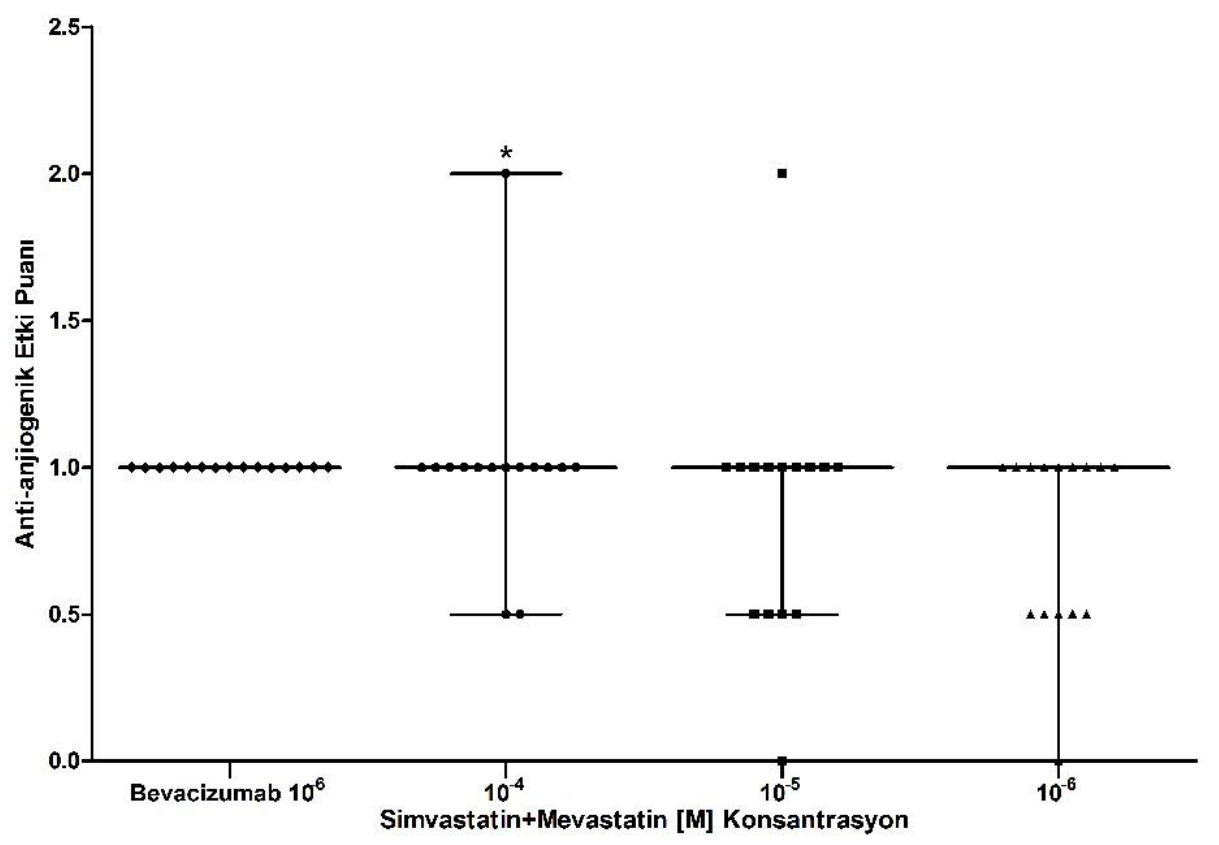

Şekil 3. Simvastatin ve mevastatinin tek başlarına $10^{-4} \mathrm{M}, 10^{-5} \mathrm{M}$ ve $10^{-6} \mathrm{M}$ konsantrasyon oluşturan miktarlarının 1:1 oranındaki kombinasyonunun antianjiyogenik etki puanları. Veriler skatter grafikte ortanca (interkuartil \% 25-75 aralık) olarak sunulmuştur.

Tablo 3. Antianjiogenik etki puanlarının karşılaştırılması.

\begin{tabular}{llll}
\hline \multicolumn{4}{c}{ Konsantrasyon } \\
\hline & $10-4 \mathrm{M}$ & $10-5 \mathrm{M}$ & $10-6 \mathrm{M}$ \\
\hline Bevacizumab & $1,58^{* *}$ & $1,55^{* *}$ & $1,00^{* *}$ \\
Simvastatin & 0,93 & 0,66 & 0,53 \\
Mevastatin & 1,0 & $0,80^{*}$ & $0,66^{*}$ \\
Simvastatin+Mevastatin & 0,96 & 0,77 & 0,59 \\
\hline *Simvastatin grubuna göre istatistiksel olarak anlamlı şekilde farklı $(\mathrm{p}<0,05)$ \\
**Tüm gruplara göre istatistiksel olarak anlaml şekilde farklı $(\mathrm{p}<0,05)$ \\
\hline
\end{tabular}

\section{Tartışma}

Anjiogenez mevcut vasküler oluşumlardan yeni vasküler yapıların teşkil etmesi olarak tanımlanmıştır [20]. Anjiogenez vücutta hem fizyolojik hem de patolojik birçok süreçte önemli rol oynamakta ve birçok hastalığın etiyopatogenezinde yer almaktadır [22,23]. Anjiogenez oluşurken birçok olay basamaklar şeklinde birbirini izler. İlk önce anjiogeneze neden olan bir etken ya da uyarı oluşmakta (örneğin hipoksi ya da iskemi) daha sonra bu etkenden dolayı anjiogenik faktörlerin salınması ve bu faktörlerin bazal membranın parçalanmasına, endotel hücrelerinin aktivasyonuna, adezyonuna, göçüne, çoğalmasına ve tüp oluşumuna neden olması ve sonuç olarak mevcut damar ağından yeni kan damarlarının oluşması şeklinde gerçekleşmektedir [24]. Statinler, düşük dansiteli lipoproteinin (DDL) düşürülmesinde ilk tercih ilaçlardır. Aynı zamanda total kolesterolün düşürülmesinde de fayda sağlarlar [25]. Statinlerin anjiogenez üzerindeki etkileri tartışmalıdır. Bazı çalışmalar statinlerin anjiogenezi indüklediğini ifade ederken, bazıları statinlerin antianjiogenik etkileri olduğunu belirtmektedir. Chade ve ark. [26]; ratlarda renal iskemi modeli geliştirmişler ve uzun süreli simvastatin tedavisinin bu renal iskemi üzerine olan etkilerini incelemişlerdir. Yapmış oldukları uzun takip sonucunda simvastatin tedavisinin renal anjiogenez ve arteriogenezi artırdığını ve renal fonksiyonların onarılmasına katkıda bulunduğunu göstermişlerdir. Nishimoto-Hazuku ve ark. [27] özellikle hipoksik koşullarda simvastatin uygulamasının, yeni damar gelişimi 
için elzem faktörlerden biri olan VEGF miktarını artırdığını, hatta bunu ekspresyon düzeyinde yaptığını göstermişlerdir. Çalışmalarını, bu artışın mekanizması çözmek üzerine genişlettiklerinde, simvastatin uygulamasının endoteliyal hücrelerdeki RhoA ekspresyonunu azaltarak ve HIF-1 $\alpha$ ekspresyonunu artırarak VEGF miktarını artırdığını tespit etmişlerdir. Zacharek ve ark. [28]; inme geçirmeleri sağlanmış ratlarda, simvastatin'in tedavi dozlarında anjiogenezi artırdığını, damarları stabilize ettiğini ve arteriyogenezi artırdığını göstermişlerdir. Bu çalışmalara zıt şekilde Zhu XY ve ark. [29] simvastatinin bozulmuş myokardiyal perfüzyon ve fonksiyon üzerindeki etkilerini araştırmışlardır. $\mathrm{Bu}$ çalışmada in-vivo olarak simvastatinin antiinflamatuar ve dolaşımı destekleyici özelliklerini ortaya koyarken, in vitro olarak anjiogenez üzerindeki etki, TNF- $\alpha$ ile indüklenmiş bir anjiogenez modeli üzerinde değerlendirilmiştir. Araştırmacılar çalışmalarında simvastatinin TNF- $\alpha$ ile indüklenmiş bir anjiogenezi belirgin şekilde inhibe ettiğini göstermişlerdir. Benzer şekilde Ahn ve ark. [30] inflamasyon ve birçok diğer hücresel olayın en önemli mediatörlerinden biri olan TNF- $\alpha$ 'nın VEGF, MMP-9 ve ICAM-1 gibi anjiogenez oluşumunda önemli rolü olan faktörlerin ekspresyonunu artırdığını, simvastatinin ise bu moleküllerin ekspresyonunu azaltarak anti anjiogenik etki meydana getirdiğini göstermişlerdir. Luo D. ve ark. [31] travmatik beyin hasarına uğramış hastalarda statinlerin etkilerini incelemişler ve simvastatinin travmatik beyin hasarına bağlı gelişen anjiogenezi azaltarak beyin fonksiyonlarının korunmasına katkıda bulunduğu ortaya koymuşlardır. Zhang ve ark. [32] ise statinlerin, anjiotensin II tarafindan indüklenen abdominal aorta anevrizmaları üzerindeki etkilerini araştırmışlardır. $\mathrm{Bu}$ çalışmada anevrizmaların yırtılmasında o bölgedeki neovaskülerizasyon ve inflamasyonun etkin olduğu ortaya konurken, statinlerin bu neovaskülerizasyon ve inflamasyonu azaltarak anevrizmaların yırtılmasını önlediği bulunmuştur. Tüm bu çelişsili çalışmalar arasında biz çalışmamızda simvastatinin CAM modelinde belirgin bir anjiogenez inhibisyonu yaptığını bulduk. Bu inhibisyon yüksek konsantrasyonlarda belirginken, düşük konsantrasyonlarla birlikte azalmıştır. Mevastatinin anjiogenez üzerindeki etkisi ile ilgili çok az veri bulunmaktadır. Var olan veriler de simvastatinde olduğu gibi çelişkilidir. Wang C. ve ark. [33] mevastatinin zevrafish intersegmental damarlarındaki anjiongenezi inhibe ettiğini göstermişlerdir. Biz de çalışmamızda tek başına mevastatin uygulamasının bizim kullandığımız yüksek konsantrasyonlarda güçlü bir anjiogenez meydana getirdiğini saptadık. Bu antianjiogenik etki benzer konsantrasyonlarda simvastatinin meydana getirmiş olduğu anti anjiogenik etkiden belirgin şekilde daha fazlayd. Hem simvastatin hem de mevastatin ile ilgili yapılan çalışmalarda anjiogenez üzerinde farklı etkilerin bulunması muhtemelen bu çalışmalarda farklı ilaç konsantrasyonları kullanılmasına ve anjiogenez üzerindeki etkinin farklı metotlarla değerlendirmesine bağlı olabilir. Urbich C. ve ark. [34] statinlerin düşük konsantrasyonlarda özellikle proanjiogenik faktörleri artırarak anjiogenezi artırıcı etki gösterirken, daha yüksek konsantrasyonlarda endotelial hücrelerde apopitozisi tetikleyerek antianjiogenik etki gösterdikleri ortaya konmuştur. $\mathrm{Bu}$ bulgu, bizim çalışmamızda kullanılan konsantrasyonlarda, simvastatin ve mevastatinin göstermiş olduğu antianjiogenik etkiyi açıklamaktadır. Bizim çalışmamızda simvastatin ve mevastatinin tek başlarına uygulamalarının yanında kombine olarak uygulamalarının anjiogenez üzerindeki etkisi de değerlendirilmiştir. Literatür incelendiğinde ne klinik kullanımda ne de deneysel çalışmalarda statinlerin kombine şekilde kullanımı ile ilgili geniş bilgilere rastlanmamaktadır. Bizim çalışmamızda statinlerin kombine olarak uygulanması herhangi ek bir etki meydana getirmemiştir. Bunun muhtemel sebebi bu iki statinin anjiogenez üzerinde meydana getirmiş oldukları etkiyi benzer etki mekanizmaları üzerinden gösteriyor olmalarıdır. Bu sonuç bu iki statinden herhangi birinin ek bir etki mekanizmasının olmadığını da düşündürmektedir.

Sonuç olarak; simvastatin ve mevastatin çalışmamızda kullanılan $10^{-4}, 10^{-5}$ ve $10^{-6} \mathrm{M}$ konsatrasyonlarda CAM modelinde anti anjiogenik etki gösteren statinlerdir. Statinlerin lipid düşürücü etkileri yanında anti inflamatuar ve antioksidan özelliklerinden faydalanılmak istendiğinde, anjiogenez inhibisyonu sağlanarak; plak içi anti anjiogenik 
etkiyle, plak rüptürü ve buna bağlı ciddi komplikasyonlardan korunmak için bu iki ajan umut vaat edici seçenekler olacaktır. Ancak bu ajanların anjiogenez üzerindeki etkilerinin daha iyi anlaş1labilmesi ve klinikte bu amaçla kullanılabilmeleri için insanlar üzerinde yapılacak daha ileri araştırmalara gerek vardır.

\section{Kaynaklar}

1. Carmeliet P. Angiogenesis in health and disease. Nat Med 2003; 9: 653-60.

2. Folkman J, Klagsbrun M. Angiogenic factors. Science 1987; 235: 442-7.

3. Risau W. Mechanisms of angiogenesis. Nature 1997; 386: 671-4.

4. Haubner R. Alphavbeta3-integrin imaging: a new approach to characterise angiogenesis? Eur J Nucl Med Mol Imaging 2006; 33 Suppl 1: 54-63.

5. Greenberg DA, Jin K. From angiogenesis to neuropathology. Nature 2005; 438: 954-9.

6. Plosker GL, McTavish D. Simvastatin. A reappraisal of its pharmacology and therapeutic efficacy in hypercholesterolaemia. Drugs 1995; 50: 334-63.

7. Kayaalp O. Rasyonel Tedavi Yönünden Tıbbi Farmakoloji 1995 Cilt-1, Feryal Matbaacilik, Ankara.

8. Tobert JA. Lovastatin and beyond: the history of the HMG-CoA reductase inhibitors. Nat Rev Drug Discov 2003; 2: 517-26.

9. Horiuchi N, Maeda T. Statins and bone metabolism. Oral diseases 2006; 12: 85101.

10. Alegret M, Silvestre JS. Pleiotropic effects of statins and related pharmacological experimental approaches. Methods Find Exp Clin Pharmacol 2006; 28: 627-56.

11. Garrett IR, Gutierrez G, Mundy GR. Statins and bone formation. Cur Pharm Des 2001; 7: 715-36.

12. Stancu C, Sima A. Statins: mechanism of action and effects. J Cell Mol Med 2001; 5: 378-87.

13. Maron DJ, Fazio S, Linton MF. Current perspectives on statins. Circulation 2000; 101: 207-13.

14. Dupuis J, Tardif JC, Cernacek P, Théroux P. Cholesterol reduction rapidly improves endothelial function after acute coronary syndromes. The RECIFE (reduction of cholesterol in ischemia and function of the endothelium) trial. Circulation 1999; 99:3227-33.

15. Leung WH, Lau CP, Wong CK. Beneficial effect of cholesterol-lowering therapy on coronary endothelium-dependent relaxation in hypercholesterolaemic patients. Lancet 1993; 341: 1496-500.

16. Kaesemeyer WH, Caldwell RB, Huang J, Caldwell RW. Pravastatin sodium activates endothelial nitric oxide synthase independent of its cholesterol-lowering actions. J Am Coll Cardiol 1999; 33: 234-41.

17. Jorge PA, Osaki MR, de Almeida E. Rapid reversal of endothelial dysfunction in hypercholesterolaemic rabbits treated with simvastatin and pravastatin. Clin Exp Pharmacol Physiol 1997; 24: 948-53.

18. Katz MS. Therapy insight: Potential of statins for cancer chemoprevention and therapy. Nature clinical practice. Oncology 2005; 2: 82-9.

19. Wolfrum S, Grimm M, Heidbreder M, Dendorfer A, Katus HA, Liao JK, Richardt G. Acute reduction of myocardial infarct size by a hydroxymethyl glutaryl coenzyme a reductase inhibitor is mediated by endothelial nitric oxide synthase. J Cardiovasc Pharmacol 2003; 41: 474-80.

20. Taylor, PC. Serum vascular markers and vascular imaging in assessment of rheumatoid arthritis disease activity and response to therapy.Rheumatology (Oxford) 2005; 44: 721-8.

21. Bürgermeister J, Paper DH, Vogl H, Linhardt RJ, Franz G. LaPSvS1, a (1-->3)beta-galactan sulfate and its effect on angiogenesis in vivo and in vitro. Carbohydr Res 2002; 337: 1459-66. 
22. Rosen L. Antiangiogenic strategies and agents in clinical trials. Oncologist 2000; 5: 20-7.

23. Wickström SA, Alitalo K, Keski-Oja J. An Endostatin-derived Peptide Interacts with Integrins and regulates Actin Cytoskeleton and Migration of Endothelial Cells. J Biol Chem 2004; 279: 20178-85.

24. Kampa M, Nifli AP, Notas G, Castanas E. Polyphenols and cancer cell growth. Rev Physiol Biochem Pharmacol 2007; 159: 79-113.

25. Ramsay LE, Haq IU, Jackson PR, Yeo WW, Pickin DM, Payne JN. Targeting lipid-lowering drug therapy for primary prevention of coronary disease: an updated Sheffield table. The Lancet 1996; 348: 387-8.

26. Chade AR, Zhu X, Mushin OP, Napoli C, Lerman A, Lerman LO. Simvastatin promotes angiogenesis and prevents microvascular remodeling in chronic renal ischemia. FASEB J 2006; 20: 1706-8.

27. Nishimoto-Hazuku A, Hirase T, Ide N, Ikeda Y, Node K. Simvastatin stimulates vascular endothelial growth factor production by hypoxia-inducible factor-1alpha upregulation in endothelial cells. J Cardiovasc Pharmacol 2008; 51: 267-73.

28. Zacharek A, Chen J, Cui X, Yang Y, Chopp M. Simvastatin increases notch signaling activity and promotes arteriogenesis after stroke. Stroke 2009; 40: 25460.

29. Zhu XY, Daghini E, Chade AR, Napoli C, Ritman EL, Lerman A, Lerman LO. Simvastatin prevents coronary microvascular remodeling in renovascular hypertensive pigs. J Am Soc Nephrol 2007; 18: 1209-17.

30. Ahn KS, Sethi G, Aggarwal BB. Simvastatin potentiates TNF-alpha-induced apoptosis through the down-regulation of NF-kappaB-dependent antiapoptotic gene products: role of IkappaBalpha kinase and TGF-beta-activated kinase-1. J Immunol 2007; 178: 2507. 16.

31. Lu D, Qu C, Goussev A, Jiang H, Lu C, Schallert T, Mahmood A, Chen J, Li Y, Chopp M. Statins increase neurogenesis in the dentate gyrus, reduce delayed neuronal death in the hippocampal CA3 region, and improve spatial learning in rat after traumatic brain injury. J Neurotrauma 2007; 24: 1132-46.

32. Zhang Y, Naggar JC, Welzig CM, Beasley D, Moulton KS, Park HJ, Galper JB. Simvastatin inhibits angiotensin II-induced abdominal aortic aneurysm formation in apolipoprotein E-knockout mice: possible role of ERK. Arterioscler Thromb Vasc Biol 2009; 29: 1764-71.

33. Wang C, Tao W, Wang Y, Bikow J, Lu B, Keating A, Verma S, Parker TG, Han $\mathrm{R}$, Wen XY. Rosuvastatin, identified from a zebrafish chemical genetic screen for antiangiogenic compounds, suppresses the growth of prostate cancer. Eur Urol. 2010; 58: 418-26.

34. Urbich C, Dernbach E, Zeiher AM, Dimmeler S. Double-edged role of statins in angiogenesis signaling. Circ Res 2002; 90: 737-44. 